\title{
Dedication: Dr. Michele L. Dionne (1954-2012)
}

\author{
Richard A. MacKenzie ${ }^{1} \cdot$ Celia Chen $^{2} \cdot$ Jenn Dijkstra $^{3}$
}

Received: 21 April 2015 / Accepted: 3 May 2015 / Published online: 15 May 2015

(C) Coastal and Estuarine Research Federation (outside the USA) 2015

In July 2012, the estuarine and coastal research and conservation community lost one of its greatest champions with the passing of Dr. Michele L. Dionne. Throughout her career, Michele's contribution to coastal conservation extended well beyond her insights into research. She was tireless in her campaign to advance our understanding of salt marsh ecology, conservation, and restoration. Her love of coastal systems made her a visionary and a fighter. She was unselfish. When she did something, it was for her community, her students, or the coastal ecosystems she was charged to protect and conserve. She had the ability to think outside of the box, to see the forest through the trees or the nekton through the mummichogs.

Michele began her scientific journey by receiving a Bachelor of Arts in Biology from Bates College in 1977. She then went on to get her Master of Science in Zoology from the University of North Carolina at Chapel Hill in 1982 where she studied the importance of cannibalism in fish populations. She continued her graduate studies by receiving a $\mathrm{PhD}$ in Biology from Dartmouth College in 1991 where she investigated habitat complexity and fish behavior. After graduating from Dartmouth College, Michele went on to become the first

Communicated by Iris C. Anderson

Richard A. MacKenzie

rmackenzie@fs.fed.us

Celia Chen

celia.chen@dartmouth.edu

Jenn Dijkstra

jdijkstra@ccom.unh.edu

1 USDA Forest Service, Pacific Southwest Research Station, Institute of Pacific Islands Forestry, 60 Nowelo St., Hilo, HI 96721, USA

2 Department of Biological Sciences, Class of '78 Life Sciences Center, HB 6044, Dartmouth College, Hanover, NH 03755, USA

3 Center for Coastal and Ocean Mapping, University of New Hampshire, 24 Colovos Road, Durham, NH 03824, USA scientist and Director of Research at the newly created Wells National Estuarine Research Reserve (WNERR).

During her tenure as the Director of Research at WNERR, she transformed the research capabilities of the reserve by generating millions of external research funds that went into building the Coastal Ecology Center that serves to house and provide modern laboratory facilities for internal research and education, external research scientists, and graduate students. This facility has and continues to nurture cadres of future ecologists and conservationists, as well as provides the infrastructure needed for well-established scientists to continue doing research in marshes and other coastal ecosystems throughout New England. Her efforts also went into garnering a trust that provides funds for a post-doctoral fellow to perform high-level research in conservation ecology. Michele, her students, and post-doctoral fellows performed a variety of research activities that included studying the utilization of marsh ecosystems by fish (Dionne et al. 1999; MacKenzie and Dionne 2008), coastal restoration (Burdick and Dionne 1994; Burdick et al. 1997; Koniski et al. 2006), assessing human and climate threats on coastal systems (Chen et al. 2009; Crain et al. 2009; Dijkstra et al. 2013; Eberhardt et al. 2011), and investigating species-specific interactions in marsh ecosystems (Dijkstra et al. 2012; Tyrrell et al. 2012). She was a proponent of long-term monitoring that could provide effective baseline data sets to determine the conditions of these ecosystems (Neckles and Dionne 2000). Once asked if there was any part of research she didn't find interesting. She replied with an emphatic, "No! I enjoy all aspects of research!".

While Michele was successful in publishing papers and book chapters on marsh ecology and conservation, it was her unwavering support of undergraduate students, graduate students, and post-doctoral students that best describes the legacy she has left behind. She provided opportunities for so many students to discover and to grow; many of these students are now ecologists and conservationists at institutions across North America. She can still be seen today in the many presentations her students or colleagues give at the Coastal and 
Estuarine Research Federation, the American Fisheries Society, or the Society of Wetland Scientists. Her presence can also be seen in the papers published in this special section dedicated to her. These papers represent only a small portion of the students and scientists that she has influenced, and this special issue continues her vision and pursuit of an increased understanding of how these ecosystems function as well as how to better protect and conserve them. We are deeply grateful to Michele and feel fortunate to have been inspired by her passion for science, conservation, and life.

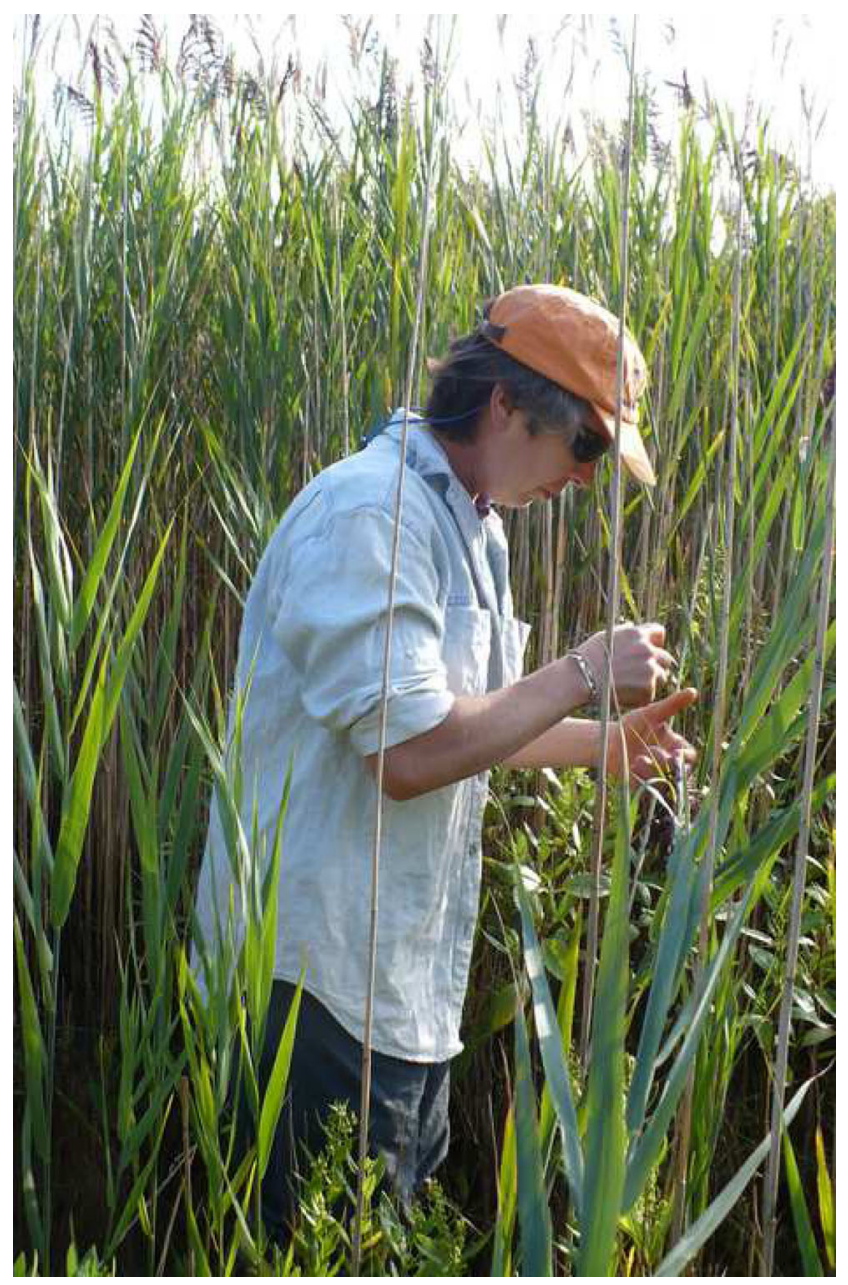

\section{References}

Burdick, D., and M. Dionne. 1994. Comparison of salt marsh restoration and creation techniques in promoting native vegetation and functional values. New Hampshire Coastal Program.

Burdick, D., M. Dionne, R. Boumans, and F. Short. 1997. Ecological responses to tidal restoration in two New England salt marshes. Wetlands Ecology and Management 4: 129-144.

Chen, C.Y., M. Dionne, B.M. Mayes, D.M. Ward, S. Sturup, and B.P. Jackson. 2009. Mercury bioavailability and bioaccumulation in estuarine food webs in the Gulf of Maine. Environmental Science \& Technology 43: 1804-1810.

Crain, C.M., K. Gedan, M. Dionne, B. Silliman, and B. Grosholz. 2009. Tidal restrictions and mosquito ditching in New England marshes. Berkeley: University of California Press.

Dijkstra, J.A., J. Boudreau, and M. Dionne. 2012. Species-specific mediation of temperature and community interactions by multiple foundation species. Oikos 121: 646-654.

Dijkstra, J.A., K.L. Buckman, D.W. Ward, D.W. Evans, M. Dionne, and C.Y. Chen. 2013. Experimental and natural warming elevates mercury concentrations in estuarine fish. PLOS ONE 8, e58401.

Dionne, M., F.T. Short, and D.M. Burdick. 1999. Fish utilization of restored, created, and reference salt-marsh habitat in the Gulf of Maine. American Fisheries Society Symposium 22: 384-404.

Eberhardt, A.L., D.M. Burdick, and M. Dionne. 2011. The effects of road culverts on nekton in New England salt marshes: Implications for tidal restoration. Restoration Ecology 19: 776-785.

Koniski, R.A., D.M. Burdick, M. Dionne, and H.A. Neckles. 2006. A regional assessment of salt marsh restoration and monitoring in the Gulf of Maine. Restoration Ecology 14: $516-525$.

MacKenzie, R.A., and M. Dionne. 2008. Habitat heterogeneity: The importance of salt marsh pools and high marsh surfaces to fish production in two Gulf of Maine salt marshes. Marine Ecology Progress Series 368: 217-230.

Neckles, H.A., and M. Dionne. 2000. Regional standards to identify and evaluate tidal wetland restoration in the Gulf of Maine. Wells National Estuarine Research Reserve Technical Report, Wells, ME: 21.

Tyrrell, M., M. Dionne, and S. Eberhard. 2012. Salt marsh fucoid algae: Overlooked ecosystem engineers of north temperate salt marshes. Estuaries and Coasts 35. 